\title{
CORRECTION
}

\section{Correction to: Risk Factors for Progression from Subclinical to Clinical Phase of Psoriatic Arthritis: A Case-Control Study}

\author{
Yiyi Wang $\cdot$ Li Ding $\cdot$ Jihui Chen $\cdot$ Lingyan Zhang $\cdot$ Min Yang \\ Zhibin Liu · Liangliang Cheng · Tianjiao Lan · Gaojie Li · \\ Yuanxia Gu $\cdot$ Yi Liu $\cdot$ Wei Li (D)
}

Published online: September 2, 2021

(C) The Author(s) 2021

Correction to: Rheumatol Ther (2021) 8:585-597

https://doi.org/10.1007/s40744-021-00295-y

In the original article published, the author contribution is missing. The correct details are given below:

Author contribution: Yiyi Wang, Li Ding and Jihui Chen contributed equally to this work.

The original article has been corrected.

Yiyi Wang, Li Ding and Jihui Chen contributed equally to this work.

The original article can be found online at https://doi. org/10.1007/s40744-021-00295-y.

Y. Wang · L. Ding · J. Chen · G. Li · Y. Gu · W. Li $(\bowtie)$

Department of Dermatology \& Rare Disease Center, West China Hospital, Sichuan University, Chengdu, Sichuan, China

e-mail: liweihx_hxyy@scu.edu.cn

\section{Zhang}

Department of Ultrasound \& Rare Disease Center, West China Hospital, Sichuan University, Chengdu, Sichuan, China

M. Yang · Y. Liu ( $₫)$

Department of Rheumatology \& Rare Disease Center, West China Hospital, Sichuan University,

\section{OPEN ACCESS}

This article is licensed under a Creative Commons Attribution-NonCommercial 4.0 International License, which permits any noncommercial use, sharing, adaptation, distribution and reproduction in any medium or format, as long as you give appropriate credit to the original author(s) and the source, provide a link to the Creative Commons licence, and indicate if changes were made. The images or other third party material in this article are included in the article's Creative Commons licence, unless indicated otherwise in a credit line to the material. If material is not included in the article's Creative Commons licence and

Chengdu, Sichuan, China

e-mail: yi2006liu@163.com

Z. Liu

Faculty of Medicine, Macau University of Science and Technology, Macau, China

L. Cheng

School of Public Health, Sun Yat-Sen University, Guangzhou, Guangdong, China

\section{T. Lan}

China School of Public Health and West China

Fourth Hospital, Sichuan University, Chengdu, Sichuan, China 
your intended use is not permitted by statutory regulation or exceeds the permitted use, you will need to obtain permission directly from the copyright holder. To view a copy of this licence, visit http://creativecommons.org/licenses/bync/4.0/. 